\title{
Cardiac Autonomic Profile of Soccer, Field Hockey and Basketball Players: A Comparative Study
}

\author{
Anjali Prajapat, ${ }^{1}$ Irshad Ahmad,, ${ }^{1,}$ Zoya Khan, ${ }^{1}$ Kamran Ali, ${ }^{1}$ and Mohd Ejaz Hussain ${ }^{1}$ \\ ${ }^{1}$ Centre for Physiotherapy and Rehabilitation Sciences, Jamia Millia Islamia (Central University), New Delhi, India \\ "Corresponding author: Irshad Ahmad, Centre for Physiotherapy and Rehabilitation Sciences, Jamia Millia Islamia, New Delhi-110025, India. Tel: +91-9911878341, E-mail: \\ irshi.ahmad@gmail.com
}

Received 2017 October 05; Revised 2018 January 04; Accepted 2018 January 23.

\begin{abstract}
Background: Heart rate recovery (HRR) and heart rate variability (HRV) provide information about cardiac autonomic control; which indicates the physical fitness level of athletes in different sports.

Objectives: The purpose of our study was to compare HRR and HRV profiles in collegiate male soccer, field hockey and basketball athletes, at rest and following activity.

Methods: Fifty-five male collegiate athletes (20 soccer, 18 field hockey and 17 basketball players) were recruited on the basis of inclusion criteria and exclusion criteria. HRR was obtained following a bout of sub-maximal exercise on a treadmill. Measures of HRV were assessed at rest and during the last 5 minutes of a 15-min recovery period post-exercise.

Results: Soccer players showed the highest and basketball players recorded the lowest resting root mean square of successive differences (RMSSD). The value of RMSSD for basketball group was significantly lower than both soccer $(\mathrm{P}<0.001)$ and field hockey (P $=0.015)$. At rest, normalized low frequency (LFnu) and low frequency-high frequency ratio were higher for the basketball group $(\mathrm{P}<$ 0.05). Basketball players showed significantly faster heart rate recovery than soccer $(\mathrm{P}=0.017)$ and field hockey players $(\mathrm{P}<0.001)$. The post-exercise LFnu value was higher in basketball players when compared with soccer players $(\mathrm{P}=0.02)$ as well as field hockey players $(\mathrm{P}=0.001)$.

Conclusions: The results of the present study suggest that basketball players exhibit greater sympathetic outflow, at rest and following activity. The autonomic profiles of soccer and field hockey players were found to be comparable.
\end{abstract}

Keywords: Heart Rate, Sympathetic, Parasympathetic, Exercise

\section{Background}

The autonomic nervous system (ANS) exerts control over the cardiovascular system. The heart's activity at rest is primarily regulated by the parasympathetic vagal branch of ANS. Heart rate (HR) and stroke volume increase during exercise to meet the metabolic demands of active skeletal muscles of the body. Rapid tachycardia during exercise is due to withdrawal of parasympathetic response followed by sympathetic dominance phase (1). With cessation of exercise, exponential decline in the HR followed by tapering response occur until full recovery happens. This decline in the HR is primarily due to sympathetic withdrawal and subsequent return of vagal activity $(2,3)$. The heart rate recovery (HRR) depends on many factors such as intensity of the exercise, age and fitness level of the individuals. Faster HRR in individuals indicates cardiovascular protection since it is associated with higher parasympathetic activity (4).
The influence of ANS on the cardiovascular system is also seen by heart rate variability (HRV) as the variation in the beat to beat intervals. HRV is defined as "the capacity of the heart to change the interval between beats when faced with different situations, where these variations are modulated mainly by the ANS" (5). The HRV evaluation at rest, during and after exercise is an innovative approach to study the different underlying physiological control mechanisms of the body reacting to physical activity (6-8). HRV is a well-established non-invasive tool which can be used to study the effect of mental stress on autonomic control of HR (9). Both HRR and HRV are indicators of cardiac health and all-cause mortality in a clinical perspective (4). These measures are also used for exercise prescription and for evaluating the outcomes of exercise training. They also predict aerobic fitness and incidence of overtraining $(3,10$, 11).

Acute response indicates decrease in the HRV param- 
eters (e.g. root mean square of successive differences (RMSSD) and high frequency spectral power (HF)) which are vagal related indices after a single exercise bout (12). The restoration of vagal tone has been examined focusing on intensity of exercise (13-15), type of exercise $(16,17)$, exercise duration (18), recovery duration (19), recovery type (20) and cardiorespiratory fitness (21). The sympatho-vagal balance is indicated by low frequency-high frequency ratio (LF-HF ratio). If this ratio is less than 1 , there is parasympathetic predominance, whereas, ratio more than 1 reflects sympathetic predominance (9).

Soccer is the most known game in the world. Soccer players' average intensity of work during match is generally between $80 \%-90 \%$ of HRmax which consist of walking (25\% of total work), jogging (37\%), sprinting (11\%), backing (6\%), and cruising (20\%) (22). Field hockey resembles soccer in terms of physical and physiological demands of play, where the player's average velocity has been estimated to range between $2.2-2.59 \mathrm{~m} / \mathrm{s}$ and maximal (temporary) velocity up to $8.03-9.27 \mathrm{~m} / \mathrm{s}$ (23). It has been reported that field hockey players spend most time in walking (46.5\%), jogging (40.5\%), standing (7.4\%) and sprinting (1.5\%) during a match play (24), which reflects a slight difference in overall intensity compared to soccer. However, both sports largely utilize the aerobic system interspersed with short anaerobic activities. On the other hand, basketball is a game that demands intermittent bouts of high intensity. Drinkwater et al. found that in international level games, players reached up to $95 \%$ of their HRmax (25). Basketball players have been reported to spend $34.1 \%$ of the game time in running and jumping, 56.8\% in walking and 9\% in standing (26), making it a predominantly anaerobic sport. This difference in the physiology of these sports is expected to reflect in the autonomic function of athletes, as a result of exposure to long-term sport-specific drills.

Previous studies have examined the effects of sports activity (27) and competition $(28,29)$ on vagal-related HRV parameters in soccer players. Its use as a measure of performance in soccer has also been explored (30). Only one study to date has assessed cardiac autonomic response along with perceived tiredness to competitive overload in field hockey players (31). Esco and Willifiord compared cardiovascular autonomic modulation in basketball players with active healthy individuals (32). Migliaro et al. compared young sedentary, young non-sedentary (soccer and basketball players) and old sedentary individuals on RMSSD, HF and low frequency (LF) spectral of HRV (33). A body of knowledge exists comparing the somatotype, physical and psychological characteristics of soccer, field hockey and basketball players (34-38). However, the comparison of autonomic function across soccer, field hockey and basketball athletes warrants investigation.

\section{Objectives}

The purpose of our study was to evaluate the HRR and HRV parameters in collegiate male soccer, field hockey and basketball athletes.

\section{Methods}

\subsection{Participants}

Fifty-five male collegiate athletes (20 soccer players, 18 field hockey players and 17 basketball players) were recruited from M. A. K. Pataudi Sports Complex, Jamia Millia Islamia, New Delhi, India. Subjects between the age of 18 - 25 years, with BMI (body mass index) ranging from 18.9 $24.9 \mathrm{~kg} / \mathrm{m}^{2}$, indulging in sport-specific training for at least the last 3 months ( 4 - 5 days/week), and having participated in university level competition, were included in the study. Those with a history of cardiac or respiratory pathology, taking medications that alter cardiac response or recovery, diagnosed of a chronic health condition, smokers and alcoholics, were excluded. All participants gave their written consent, after verbal explanation of the procedure, risks involved and participation being entirely voluntarily. All uncertainties among the participants regarding the procedure were cleared. Prior to the experimental procedure, ethical approval for the study was granted from the institutional ethics committee, Jamia Millia Islamia, New Delhi, India.

\subsection{Instrumentation and Data Acquisition}

Measurements were undertaken in a quiet room, at a temperature between 24 to $30^{\circ} \mathrm{C}$ and at the same time (between 10:00 am and 1:00 pm) during the day to nullify the effect of circadian rhythm on HRV. Skin was prepared by wiping with alcohol swab for the electrodes placement to reduce impedance. Electrocardiograph (ECG) was recorded at rest and after sub-maximal exercise in supine lying for 10 minutes while breathing approximately at 15 breaths per minute. HRV analysis was done on final 5minute epochs segment of ECG. ECG data was sampled at $1000 \mathrm{~Hz}$, band pass filtered between 0.3 and $100 \mathrm{~Hz}$, and stored on computer for analysis (Powerlab 8/30 Data Acquisition System with LabchartPro: AD Instrument, Australia). For HRV analysis, R-R intervals were selected by setting threshold at $0.5 \mathrm{mV}$ and ectopics were excluded from analysis by "beat classifier" function of software. HR was recorded by a heart rate monitor (Polar Electro, RS 400, Kempele, Finland) with chest strap. 


\subsection{Procedure}

Subjects were instructed to lie down supine for $10 \mathrm{~min}-$ utes to attain complete relaxation during which, resting heart rate (RHR) and HRV were recorded. Following this, the participants performed an incremental treadmill test at sub-maximal exercise intensity. A 5 - 10 min familiarization session for treadmill running was given to each participant 24 hours before actual testing. The incremental running test began with an initial speed of $8 \mathrm{~km} / \mathrm{h}$ with grade 0 and increased $1 \mathrm{~km} / \mathrm{h}$ every minute until the subject reached sub-maximal target heart rate (THR), experienced adverse signs or symptoms, requested to stop, or experienced any emergency situation. Beat-by-beat HR responses were monitored during the running test. The THR was calculated using Karvonen formula, THR $=[($ HRmax RHR) $\times 80 \%-85 \%$ Intensity] + RHR, where maximal heart rate, $\mathrm{HRmax}=206.9-0.69 \times$ age (years).

After the exercise protocol, subjects returned to supine lying within 5 seconds. HRR was recorded at 1st, 2nd and 3rd minutes, post-exercise. The subject remained in this position for 15 minutes, during the final 5 minutes subjects were instructed to breathe at a frequency of around 15 breaths per minute. Talking and excessive movement during this time period was avoided. ECG was recorded for 10 minutes, but to ensure being stationary, the final 5 minutes were used to analyze HRV. Time domain HRV measures were obtained by mean RR intervals (meanNN) and the root mean square of successive differences (RMSSD) whereas frequency domain measures of HRV were derived by Fast Fourier Transformation: they were low-frequency (LF; $0.04-0.15 \mathrm{~Hz}$ ) and high-frequency (HF; $0.15-0.4 \mathrm{~Hz}$ ) spectral power. Temporal and spectral measures of HRV have been reported to be reliable and reproducible by previous literature $(7,39)$ (Figure 1).

\subsection{Statistical Analysis}

Data were analyzed using SPSS version 21. The ShapiroWilk test was used to verify the normality of distribution for all variables. RHR and RMSSD scores that demonstrated non-normal distribution were log transformed for further analysis. The demographic characteristics and baseline measures were compared between the groups using oneway ANOVA. A repeated measure ANOVA was used for HRR. $3 \times 2$ mixed model ANOVA was employed for meanNN, HFnu to find out main effect of group (soccer, field hockey and basketball) and time (resting, post-exercise) as well as Group $\times$ Time interaction. $3 \times 2$ mixed model ANCOVA was used for RMSSD, LFnu and LF-HF ratio considering baseline measures as covariate. Post hoc Bonferroni test was used for multiple comparisons. Statistical significance level was kept at $\mathrm{P} \leq 0.05$.

\section{Results}

Demographic characteristics showed no significant difference between the groups in age, BMI, RHR and THR while significant differences were found in weight $\left(\mathrm{F}_{2,52}=\right.$ 9.298, $\mathrm{P}<0.001)$ and height $\left(\mathrm{F}_{2,52}=4.003, \mathrm{P}=0.024\right)$. Post hoc analyses showed that basketball players are taller than soccer players and heaviest among the 3 groups (Table 1 ).

HRR showed significant group effect $\left(\mathrm{F}_{2,52}=10.34, \mathrm{P}\right.$ $<0.001)$, time effect $\left(\mathrm{F}_{3,52}=2012.08, \mathrm{P}<0.001\right)$ and group $\times$ time interaction effect $\left(\mathrm{F}_{6,52}=10.72, \mathrm{P}<0.001\right)$. Post hoc revealed that basketball players showed faster HRR than soccer $(\mathrm{P}=0.017)$ and field hockey players $(\mathrm{P}<0.001)$ during first 3 minutes of recovery after exercise. Also the decrease in the heart rate is significant in first minute, second minute and third minute in soccer $(\mathrm{P}<0.001)$, field hockey $(\mathrm{P}<0.001)$ as well as basketball players $(\mathrm{P}<0.001)$ Figure 2.

Time and frequency domains of HRV measures of soccer, field hockey and basketball players at rest are presented in Table 2 . At baseline, no significant difference was found in meanNN $\left(\mathrm{F}_{2,52}=1.656, \mathrm{P}=0.201\right)$ as well as HFnu $\operatorname{spectral}\left(\mathrm{F}_{2,52}=1.085, \mathrm{P}=0.345\right)$ of HRV parameters among the groups. While significant differences were found in $\operatorname{RMSSD}\left(\mathrm{F}_{2,52}=14.715, \mathrm{P}<0.001\right), \operatorname{LFnu}\left(\mathrm{F}_{2,52}=4.33, \mathrm{P}=0.018\right)$ and LF-HF ratio $\left(\mathrm{F}_{2,52}=3.168, \mathrm{P}=0.05\right)$. Post hoc revealed that soccer players showed higher value RMSSD than field hockey (45.77\%) and basketball players (157.77\%), also field hockey players were higher than basketball players (76.83 $\%$ ) in that regard. Basketball players showed higher LF-HF ratio than soccer players (43.12\%) and higher LFnu values than soccer (32.23\%) as well as field hockey players (30.64\%) (Table 2). Mixed analysis of variance revealed that there was no significant difference between the groups at post exercise recovery in meanNN $\left(\mathrm{F}_{2,51}=0.273, \mathrm{P}=0.762\right)$, RMSSD $\left(F_{2,51}=2.371, \mathrm{P}=0.104\right)$, HFnu $\left(\mathrm{F}_{2,51}=2.194, \mathrm{P}=0.122\right)$ and LFHF ratio $\left(\mathrm{F}_{2,52}=1.114, \mathrm{P}=0.336\right)$ while there was significant difference showed in LFnu spectral power $\left(\mathrm{F}_{2,52}=7.629, \mathrm{P}\right.$ $=0.001)$. Post hoc revealed that there was a higher LFnu value in basketball players than soccer players as well as field hockey players (Table 3).

Relative changes in time and frequency domain HRV parameters at baseline and post-exercise are presented in Figure 3. Post-exercise meanNN, RMSSD and HFnu measures of HRV were significantly lower compared with baseline values with $\mathrm{F}_{1,52}=147.29, \mathrm{P}<0.001, \mathrm{~F}_{1,52}=8.329, \mathrm{P}$ $=0.006$, and $F_{1,52}=136.07, \mathrm{P}<0.001$ respectively. Postexercise LFnu and LF-HF ratio were significantly increased during recovery when compared to baseline values with $\mathrm{F}_{1,52}=156.01, \mathrm{P}<0.001$ and $\mathrm{F}_{1,52}=18.51, \mathrm{P}<0.001$ respectively. 


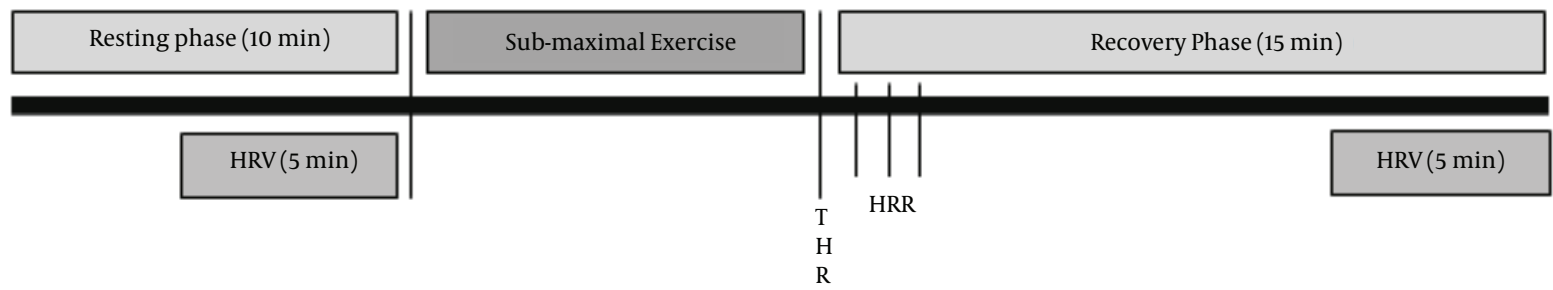

Figure 1. Evaluation of HRR and HRV

\begin{tabular}{|c|c|c|c|c|c|c|}
\hline \multirow[t]{2}{*}{ Participant Characteristics } & \multirow{2}{*}{$\begin{array}{c}\text { Soccer Players }(\mathbf{n}=\mathbf{2 0}) \\
\text { Mean } \pm \text { SD }\end{array}$} & \multirow{2}{*}{$\begin{array}{c}\text { Field Hockey Players }(\mathbf{n}=\mathbf{1 8}) \\
\text { Mean } \pm \text { SD }\end{array}$} & \multirow{2}{*}{$\begin{array}{c}\text { Basketball Players }(n=17) \\
\text { Mean } \pm \text { SD }\end{array}$} & \multicolumn{3}{|c|}{ PValue } \\
\hline & & & & S Vs FH & S Vs B & FH Vs B \\
\hline Age, $y$ & $21.10 \pm 2.12$ & $21.44 \pm 2.14$ & $20.41 \pm 1.62$ & 1 & 0.899 & 0.394 \\
\hline Weight, kg & $61.33 \pm 3.88$ & $61.43 \pm 4.73$ & $67.7 \pm 6.33$ & 1 & $0.001^{*}$ & $0.002^{*}$ \\
\hline Height, m & $1.67 \pm 0.05$ & $1.68 \pm 0.05$ & $1.72 \pm 0.06$ & 1 & $0.037^{*}$ & 0.07 \\
\hline BMI, $\mathrm{kg} / \mathrm{m}^{2}$ & $21.77 \pm 1.36$ & $21.68 \pm 1.03$ & $22.62 \pm 1.38$ & 1 & 0.142 & 0.098 \\
\hline RHR, bpm & $61.6 \pm 5.28$ & $63.22 \pm 4.44$ & $65.29 \pm 4.08$ & 0.869 & 0.060 & 0.586 \\
\hline THR, bpm & $173.1 \pm 1.37$ & $172.55 \pm 1.29$ & $173.58 \pm 1.17$ & 0.598 & 0.768 & 0.065 \\
\hline
\end{tabular}

Abbreviations: B, basketball; BMI, body mass index; FH, field hockey; RHR, resting heart rate; S, soccer; SD, standard deviation; THR, target heart rate.

\begin{tabular}{|c|c|c|c|c|c|c|}
\hline \multirow[t]{2}{*}{ Participants Characteristics } & \multirow{2}{*}{$\begin{array}{c}\text { Soccer Players }(\mathbf{n}=\mathbf{2 0}) \\
\text { Mean } \pm \text { SD }\end{array}$} & \multirow{2}{*}{$\begin{array}{l}\text { Field Hockey Players }(\mathbf{n}=\mathbf{1 8}) \\
\qquad \text { Mean } \pm \text { SD }\end{array}$} & \multirow{2}{*}{$\begin{array}{c}\text { Basketball Players }(\mathbf{n}=17) \\
\text { Mean } \pm \text { SD }\end{array}$} & \multicolumn{3}{|c|}{ PValue } \\
\hline & & & & S Vs FH & SVs B & FH Vs B \\
\hline \multicolumn{7}{|l|}{ HRV time domain } \\
\hline Mean NN, ms & $926.28 \pm 180.25$ & $853.36 \pm 81.14$ & $879.71 \pm 74.27$ & 0.238 & 0.796 & 1 \\
\hline RMSSD, ms & $102.80 \pm 46.46$ & $70.52 \pm 40.85$ & $39.88 \pm 16.42$ & $0.05^{*}$ & $<0.001^{*}$ & $0.015^{*}$ \\
\hline \multicolumn{7}{|l|}{ HRV frequency domain } \\
\hline $\mathrm{LF}, \mathrm{nu}$ & $36.14 \pm 12.93$ & $36.58 \pm 15.45$ & $47.79 \pm 11.16$ & 1 & $0.032^{*}$ & $0.048^{*}$ \\
\hline HF, nu & $46.61 \pm 11.87$ & $41.69 \pm 9.83$ & $45.35 \pm 9.67$ & 0.475 & 1 & 0.933 \\
\hline $\mathrm{LF} / \mathrm{HF}$ & $0.80 \pm 0.33$ & $0.90 \pm 0.42$ & $1.15 \pm 0.51$ & 1 & $0.05^{*}$ & 0.283 \\
\hline
\end{tabular}

Abbreviations: B, basketball players; FH, field hockey players; HF (nu), normalized high frequency spectral power; HRV, heart rate variability; LF (nu), normalized low frequency spectral power; LF/HF, low frequency/high frequency ratio; mean NN, mean RR normal to normal interval; RMSSD, root mean square of successive differences; S, soccer players; SD, standard deviation.

\section{Discussion}

The purpose of present study was to compare the autonomic control of heart in soccer, field hockey and basketball players at rest and during recovery. Previous studies have reported a more ectomorphic profile in basketball players when compared to hockey players (38). While our study did not explicitly study somatotypes, we found no significant difference between the groups in terms of BMI. The basketball group was found to be the heaviest among all three groups.

\subsection{Resting HR and HRV}

The RHR of athletes is lesser than the sedentary individuals (29), due to increased vagal tone that causes resting bradycardia which is a cardiovascular adaptation to endurance training (40). This study revealed similar RHR between the groups, indicating comparable physical fitness.

Previous studies have shown that training load significantly influences the cardiovascular autonomic activity control (21). Bricout et al. reported lesser LFnu and LF-HF ratio during rest in soccer players that increased with physical and psychological stress (27). Parrado et al. 


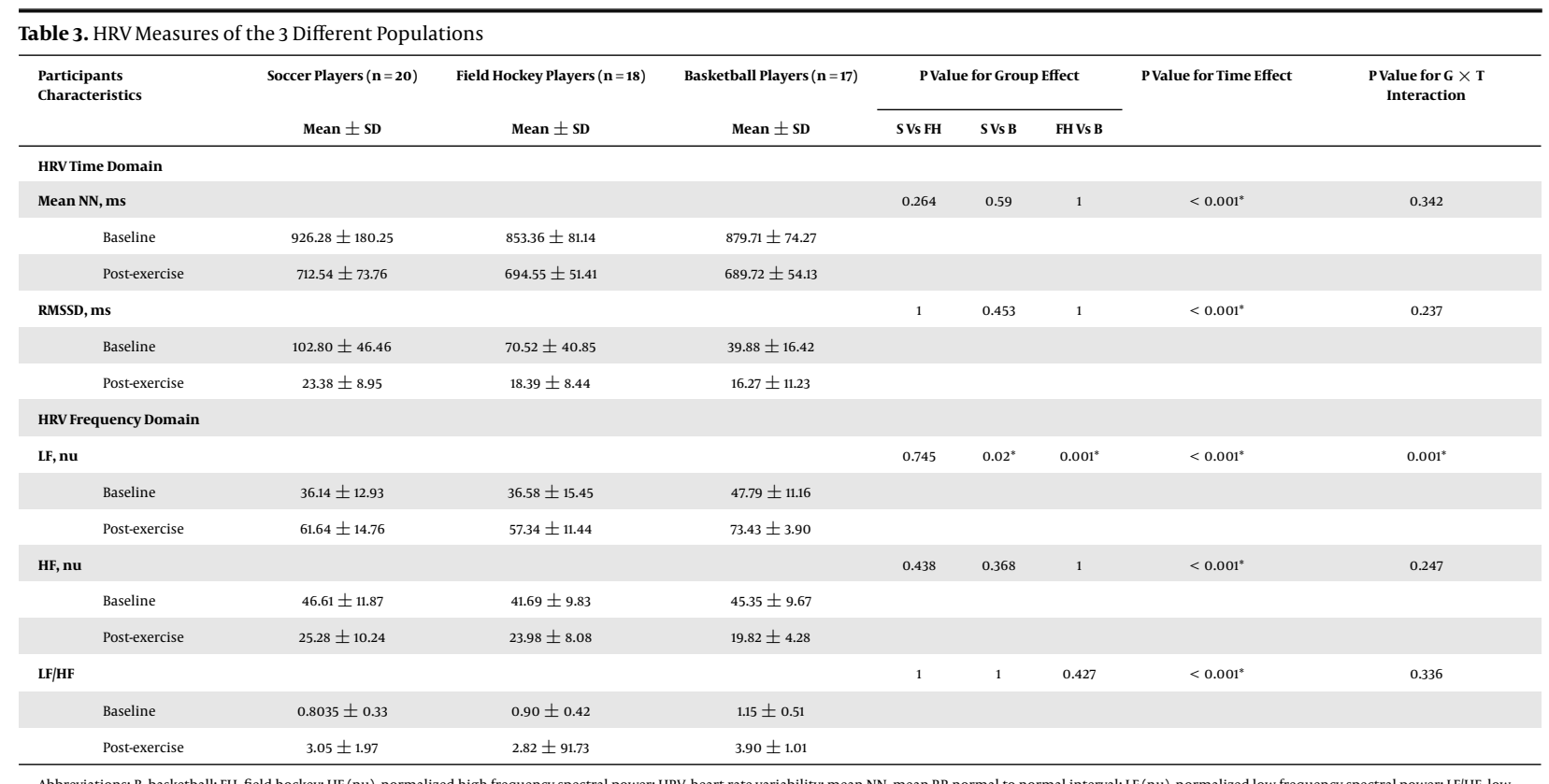

bbreviations: $\mathrm{B}$, basketball; $\mathrm{FH}$, field hockey; $\mathrm{HF}$ (nu), normalized high frequency spectral power; $\mathrm{HRV}$, heart rate vari

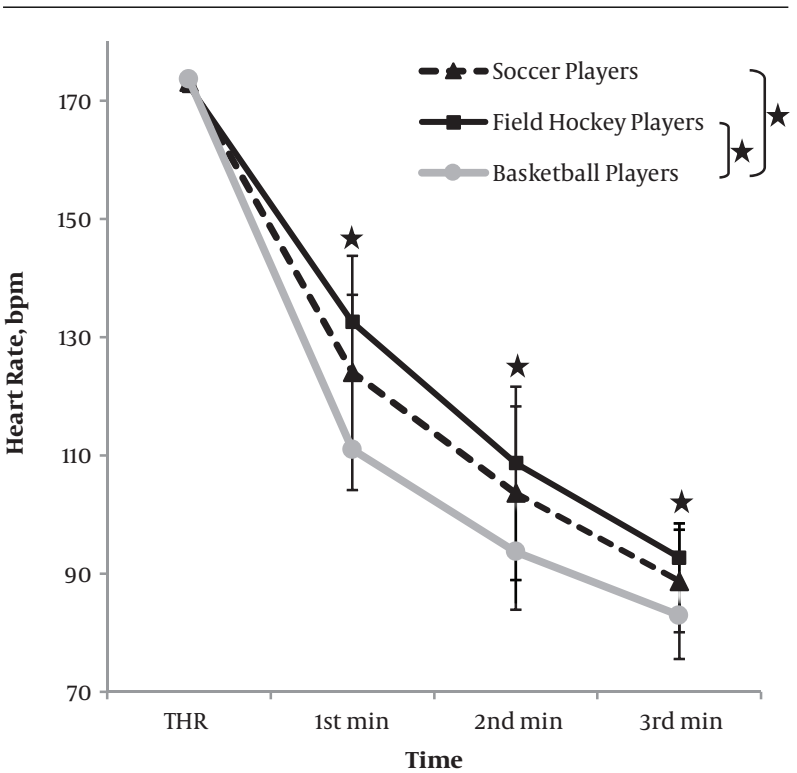

Figure 2. Changes (mean $\pm \mathrm{SD}$ ) in Heart Rate Recovery After Sub-Maximal Exercise. ${ }^{*}$ P value $<0.05$, THR: Target heart rate.

found higher value of LF-HF ratio in field hockey players showing changes in cardiac autonomic response during World Cup (31). HF indices of HRV more accurately indicate parasympathetic dominance, while RMSSD is shown to be less affected by the respiration at rest (41). RMSSD which is indicative of vagal activity was found to be signif-

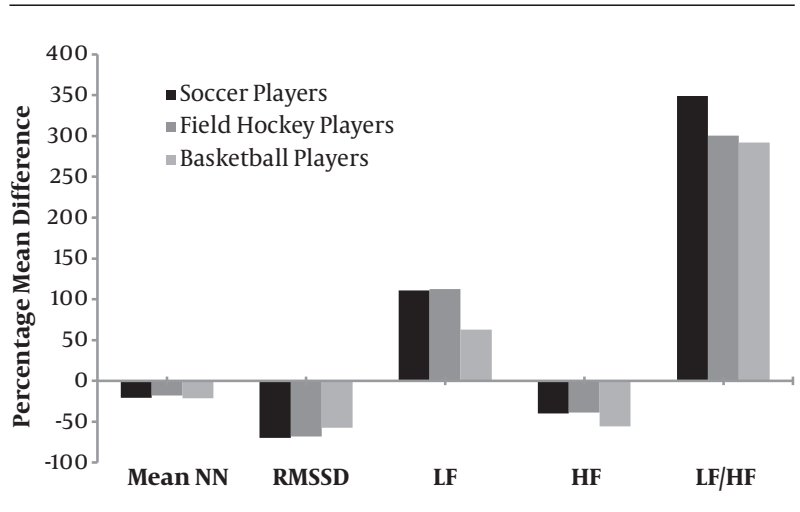

Figure 3. Relative changes in time and frequency domain HRV parameters pre and post-exercise. Mean NN: mean RR normal to normal interval; RMSSD: root mean square of successive differences; LF: low frequency spectral power; HF: high frequency spectral power; LF/HF: low frequency/high frequency ratio.

icantly lower whereas, LFnu that reflects sympathetic activation was significantly higher in the basketball group. LF-HF ratio that represents sympatho-vagal balance related to arterial baroreflex activity and cardiovascular stresses was also shown to be significantly elevated. These suggest an enhanced sympathetic and depressed parasympathetic tone at rest, in basketball players, relative to soccer and field hockey athletes. While soccer and hockey athletes were comparable in terms of HRV indices, significant differences in the profiles of basketball players were recorded. 


\subsection{Heart Rate Recovery}

Studies that have examined the relationships between HRR and physical activity, suggest that faster HRR is associated with good physical fitness $(3,42)$. The current study revealed faster HRR in the basketball players than soccer players and field hockey players. The difference found in the HRR in the first minute was about 62 beats in basketball players while for soccer and field hockey players it was about 49 beats and 40 beats respectively. This showed that the rapid change in autonomic control with sympathetic withdrawal or increased parasympathetic activity after cessation of exercise in basketball players was higher relative to soccer players and field hockey players. This could be attributed to the frequent, short-burst, sprinting activity in basketball. Faster HRR has been shown to be associated with sprinting (43). With the repeated bouts of high intensity activity and recovery bout over a period of time, adjustments in ANS could be expected, that might control the activity of heart via return of vagal tone. Studies have shown that athletes who engage in intermittent endurance sports have faster HRR than athletes involved in continuous endurance sports after maximal exercise (44). Also, previously found $1 \mathrm{~min}$ HRR to be about 40 beats in the first minute after exercise for soccer players as well as in sedentary during the competition (29). Although our study was performed during the competitive season, level of competition could be the reason for the difference because the participants were in the middle of intra-university competition.

\subsection{Post-Exercise HRV}

This study incorporated a submaximal exercise followed by 15 minutes of recovery in supine showing altered autonomic control post-exercise. RMSSD (69.79\% in soccer players, $67.96 \%$ in field hockey players and $57.41 \%$ in basketball players) and HFnu indices (40.09\% in soccer players, $38.58 \%$ in field hockey players and $55.48 \%$ in basketball players) of HRV showed significant reduction after 15 minutes of recovery when comparing with the baseline values; indicating lesser parasympathetic activity. We also found elevated LFnu (110.58\% in soccer player and $112.73 \%$ in field hockey players and $62.98 \%$ in basketball players) and LF/HF ratio post recovery increased sympathetic outflow to the heart. The difference in resting and post-exercise values of HRV signifies that the shift in autonomic modulation during exercise did not return to resting levels. The findings are consistent with previous studies that emphasize parasympathetic withdrawal and increased sympathetic tone elicited during activity. Moreover, as demonstrated by Barak et al., Terziotti et al., Parekh and Lee, and Kamath et al. the recovery following activity was not completed in
15 minutes. Both the depressed vagal and elevated sympathetic tone failed to return to resting levels within the recovery period following exercise $(14,15,20,45)$.

The results of post-exercise HRV demonstrated an overall reduction in the indices of vagal activity and increase in the markers of sympathetic tone. This is expected, as the transition from rest to exercise entails parasympathetic withdrawal and sympathetic up regulation in order to raise the metabolic rate and meet the energy demands of physical activity. This elevated sympathetic outflow and reduced parasympathetic reactivation even after 15 minutes of exercise recovery could be due to the following i) increased level of metabolites, ii) elevation of catecholamines and other sympathetic transmitters and iii) arterial baroreflex stimulation during the exercise (46-48).

The magnitude of recovery (difference of resting and post-exercise HRV) was similar between the 3 groups for all variables except LFnu. LFnu which denotes sympathetic activity was found to be increased in all groups post-exercise but the increase was significantly greater in the basketball group. These sports have different aerobic and anaerobic contribution during the game, the player's effort during the game, found to be $70 \%$ of the player's effort in a field hockey game, $80 \%$ of player's effort in a soccer and $50 \%$ in the basketball in terms of aerobic demands (49-51). The aerobic fitness shifted the autonomic power distribution more towards parasympathetic activation (52). Moreover, increased sympathetic dominance in basketball players can be due to increased metabolites as a consequence of repeated anaerobic bouts of activity. Further changes in HRV might not be explained merely by the reflex mechanism, but weakening of baroreflex activity influence on post exercise autonomic control over cardiovascular activity.

Thus, it is reasonable that the current study explained the difference in the autonomic contribution in these different sports and gives cardiovascular fitness profile of athletes. This information is useful for incorporating different training methodologies or development of a specific training program for cardio-respiratory fitness in athletes. There was some limitation in the study. The type of training and amount of training done by the participating athletes was not fully explained in the study, although the training load is somewhat included into the inclusion criteria. Also, there was greater relation of HRV measures to the training load in the athletic population. Further research can be focused on considering the physiological (primarily aerobic and anaerobic) and psychological characteristics in these athletic groups.

In conclusion, the results of the present study suggest that basketball players exhibit greater sympathetic outflow, at rest and following activity. The autonomic profiles 
of soccer and field hockey were found to be comparable.

\section{Acknowledgments}

The authors are grateful to Prof. Iqtidar Mohd khan, Director, Games and Sports, Jamia Millia Islamia for their assistance in recruiting the participants. Sincere thanks to Dr. Jamal Ali Moiz, Centre for Physiotherapy and Rehabilitation Sciences, Jamia Millia Islamia, New Delhi for his advice regarding the statistical analysis of the data.

\section{Footnote}

Conflict of Interests: The authors have no conflict of interest to declare.

\section{References}

1. Goldsmith RL, Bloomfield DM, Rosenwinkel ET. Exercise and autonomic function. Coron Artery Dis. 2000;11(2):129-35. [PubMed: 10758814].

2. Goldberger JJ, Le FK, Lahiri M, Kannankeril PJ, Ng J, Kadish AH. Assessment of parasympathetic reactivation after exercise. Am J Physiol Heart Circ Physiol. 2006;290(6):H2446-52. doi: 10.1152/ajpheart.01118.2005. [PubMed: 16415073].

3. Imai K, Sato H, Hori M, Kusuoka H, Ozaki H, Yokoyama H, et al. Vagally mediated heart rate recovery after exercise is accelerated in athletes but blunted in patients with chronic heart failure. J Am Coll Cardiol. 1994;24(6):1529-35. [PubMed: 7930286].

4. Cole CR, Foody JM, Blackstone EH, Lauer MS. Heart rate recovery after submaximal exercise testing as a predictor of mortality in a cardiovascularly healthy cohort. Ann Intern Med. 2000;132(7):552-5. [PubMed: 10744592].

5. Sztajzel J. Heart rate variability: a noninvasive electrocardiographic method to measure the autonomic nervous system. Swiss Med Wkly. 2004;134(35-36):514-22. [PubMed: 15517504].

6. Sandercock GR, Brodie DA. The use of heart rate variability measures to assess autonomic control during exercise. Scand J Med Sci Sports. 2006;16(5):302-13. doi: 10.1111/j.1600-0838.2006.00556.x. [PubMed: 16774653].

7. Nunan D, Donovan G, Jakovljevic DG, Hodges LD, Sandercock GR, Brodie DA. Validity and reliability of short-term heart-rate variability from the Polar S810. Med Sci Sports Exerc. 2009;41(1):243-50. doi: 10.1249/MSS.ob013e318184a4b1. [PubMed: 19092682].

8. de la Cruz Torres B, Lopez Lopez C, Naranjo Orellana J. Analysis of heart rate variability at rest and during aerobic exercise: a study in healthy people and cardiac patients. Br J Sports Med. 2008;42(9):715-20. doi: 10.1136/bjsm.2007.043646. [PubMed: 18199627].

9. Camm AJ, Malik M, Bigger JT, Breithardt G, Cerutti S, Cohen RJ. Heart rate variability: standards of measurement, physiological interpretation and clinical use. Task Force of the European Society of Cardiology and the North American Society of Pacing and Electrophysiology. Circulation. 1996;93(5):1043-65. [PubMed: 8598068].

10. Borresen J, Lambert MI. Autonomic control of heart rate during and after exercise : measurements and implications for monitoring training status. Sports Med. 2008;38(8):633-46. [PubMed: 18620464].

11. Hynynen E, Uusitalo A, Konttinen N, Rusko H. Cardiac autonomic responses to standing up and cognitive task in overtrained athletes. Int J Sports Med. 2008;29(7):552-8. doi: 10.1055/s-2007-989286. [PubMed: 18050058].
12. James DV, Barnes AJ, Lopes P, Wood DM. Heart rate variability: response following a single bout of interval training. Int J Sports Med. 2002;23(4):247-51. doi: 10.1055/s-2002-29077. [PubMed: 12015624].

13. Gladwell VF, Sandercock GR, Birch SL. Cardiac vagal activity following three intensities of exercise in humans. Clin Physiol Funct Imaging. 2010;30(1):17-22. doi: 10.1111/j.1475-097X.2009.00899.x. [PubMed: 19744086].

14. Parekh A, Lee CM. Heart rate variability after isocaloric exercise bouts of different intensities. Med Sci Sports Exerc. 2005;37(4):599-605. [PubMed: 15809558].

15. Terziotti P, Schena F, Gulli G, Cevese A. Post-exercise recovery of autonomic cardiovascular control: a study by spectrum and crossspectrum analysis in humans. EurJAppl Physiol.2001;84(3):187-94.doi: 10.1007/s004210170003. [PubMed: 11320634].

16. Mourot L, Bouhaddi M, Tordi N, Rouillon JD, Regnard J. Short- and long-term effects of a single bout of exercise on heart rate variability: comparison between constant and interval training exercises. Eur J Appl Physiol. 2004;92(4-5):508-17. [PubMed: 15461995].

17. Yamamoto K, Miyachi M, Saitoh T, Yoshioka A, Onodera S. Effects of endurance training on resting and post-exercise cardiac autonomic control. Med Sci Sports Exerc. 2001;33(9):1496-502. [PubMed:11528338].

18. Seiler S, Haugen $O$, Kuffel E. Autonomic recovery after exercise in trained athletes: intensity and duration effects. Med Sci Sports Exerc. 2007;39(8):1366-73. doi: 10.1249/mss.ob013e318060fi7d. [PubMed: $17762370]$

19. Pober DM, Braun B, Freedson PS. Effects of a single bout of exercise on resting heart rate variability. Med Sci Sports Exerc. 2004;36(7):1140-8. [PubMed: 15235317].

20. Barak OF, Ovcin ZB, Jakovljevic DG, Lozanov-Crvenkovic Z, Brodie DA, Grujic NG. Heart rate recovery after submaximal exercise in four different recovery protocols in male athletes and non-athletes. J Sports Sci Med. 2011;10(2):369-75. [PubMed: 24149885]. [PubMed Central: PMC3761860].

21. Buchheit M, Gindre C. Cardiac parasympathetic regulation: respective associations with cardiorespiratory fitness and training load. Am J Physiol Heart Circ Physiol. 2006;291(1):H451-8. doi: 10.1152/ajpheart.00008.2006. [PubMed: 16501030].

22. Stolen T, Chamari K, Castagna C, Wisloff U. Physiology of soccer: an update. Sports Med. 2005;35(6):501-36. [PubMed: 15974635].

23. Konarski J. Characteristics of chosen parameters of external and internal loads in eastern european high level field hockey players. $\mathrm{Ju}$ man Sport Exerc. 2010. doi: 10.4100/jhse.

24. Spencer M, Lawrence S, Rechichi C, Bishop D, Dawson B, Goodman C. Time-motion analysis of elite field hockey, with special reference to repeated-sprint activity. J Sports Sci. 2004;22(9):843-50. doi: 10.1080/02640410410001716715. [PubMed:15513278].

25. Drinkwater EJ, Hopkins WG, McKenna MJ, Hunt PH, Pyne DB. Modelling age and secular differences in fitness between basketball players. J Sports Sci. 2007;25(8):869-78. doi: 10.1080/02640410600907870. [PubMed: 17474040].

26. Narazaki K, Berg K, Stergiou N, Chen B. Physiological demands of competitive basketball. Scand J Med Sci Sports. 2009;19(3):425-32. doi: 10.1111/j.1600-0838.2008.00789.x. [PubMed:18397196].

27. Bricout VA, Dechenaud S, Favre-Juvin A. Analyses of heart rate variability in young soccer players: the effects of sport activity. Auton Neurosci. 2010;154(1-2):112-6. doi: 10.1016/j.autneu.2009.12.001. [PubMed: 20061188].

28. Buchheit M, Mendez-Villanueva A, Quod MJ, Poulos N, Bourdon P. Determinants of the variability of heart rate measures during a competitive period in young soccer players. EurJAppl Physiol.2010;109(5):86978. doi: 10.1007/s00421-010-1422-x. [PubMed: 20229253].

29. Santos Correa AP, Nazario Viecili PR, Cristina Callegaro C. Heart Rate Recovery is Blunted in Soccer Athletes During a Competitive Season.J Sports Med Doping Stud. 2015;6(1). doi: 10.4172/2161-0673.1000166. 
30. Buchheit M, Simpson MB, Al Haddad H, Bourdon PC, MendezVillanueva A. Monitoring changes in physical performance with heart rate measures in young soccer players. Eur J Appl Physiol. 2012;112(2):711-23. doi: 10.1007/s00421-011-2014-0. [PubMed: 21656232].

31. Parrado E, Cervantes J, Pintanel M, Rodas G, Capdevila L. Perceived tiredness and heart rate variability in relation to overload during a field hockey World Cup. Percept Mot Skills. 2010;110(3 Pt1):699-713. doi: 10.2466/PMS.110.3.699-713. [PubMed: 20681325].

32. Astorino T, Baker J, Brock S, Dalleck L, Goulet E, Gotshall R, et al. Cardiovascular autonomic modulation in collegiate male basketball players. J Exerc Physiol. 2011;14(1).

33. Migliaro ER, Contreras P, Bech S, Etxagibel A, Castro M, Ricca R, et al. Relative influence of age, resting heart rate and sedentary life style in short-term analysis of heart rate variability. Braz J Med Biol Res. 2001;34(4):493-500. [PubMed: 11285461].

34. Bressel E, Yonker JC, Kras J, Heath EM. Comparison of static and dynamic balance in female collegiate soccer, basketball, and gymnastics athletes. J Athl Train. 2007;42(1):42-6. [PubMed: 17597942]. [PubMed Central: PMC1896078].

35. Cowley HR, Ford KR, Myer GD, Kernozek TW, Hewett TE. Differences in neuromuscular strategies between landing and cutting tasks in female basketball and soccer athletes. J Athl Train. 2006;41(1):67-73. [PubMed: 16619097]. [PubMed Central: PMC1421490].

36. Metaxas TI, Koutlianos N, Sendelides T, Mandroukas A. Preseason physiological profile of soccer and basketball players in different divisions. J Strength Cond Res. 2009;23(6):1704-13. doi: 10.1519/JSC.ob013e3181b3e0c5. [PubMed: 19675493].

37. Sewell DF, Edmondson AM. Relationships between field position and pre-match competitive state anxiety in soccer and field hockey. Int $J$ Sport Psychol.1996;27(2):159-72.

38. Toriola AL, Salokun SO, Mathur DN. Somatotype characteristics of male sprinters, basketball, soccer, and field hockey players. Int J Sports Med.1985;6(6):344-6.doi:10.1055/s-2008-1025868. [PubMed: 4077363].

39. Sandercock GR, Bromley PD, Brodie DA. The reliability of short-term measurements of heart rate variability. Int J Cardiol. 2005;103(3):23847. doi: 10.1016/j.ijcard.2004.09.013. [PubMed:16098384].

40. Oakley D. General cardiology: The athlete's heart. Heart. 2001;86(6):722-6. [PubMed: 11711481]. [PubMed Central: PMC1730007].

41. Penttila J, Helminen A, Jartti T, Kuusela T, Huikuri HV, Tulppo MP, et al. Time domain, geometrical and frequency domain analysis of cardiac vagal outflow: effects of various respiratory patterns. Clin Physiol.
2001;21(3):365-76. [PubMed: 11380537].

42. Davis WJ, Wood DT, Andrews RG, Elkind LM, Davis WB. Concurrent training enhances athletes' cardiovascular and cardiorespiratory measures. J Strength Cond Res. 2008;22(5):1503-14. doi: 10.1519/JSC.ob013e3181739f9f. [PubMed: 18714238].

43. Buchheit M, Voss SC, Nybo L, Mohr M, Racinais S. Physiological and performance adaptations to an in-season soccer camp in the heat: associations with heart rate and heart rate variability. Scand J Med Sci Sports. 2011;21(6):e477-85. doi: 10.1111/j.1600-0838.2011.01378.x. [PubMed: 22092960].

44. Ostojic SM, Markovic G, Calleja-Gonzalez J, Jakovljevic DG, Vucetic $\mathrm{V}$, Stojanovic MD. Ultra short-term heart rate recovery after maximal exercise in continuous versus intermittent endurance athletes. Eur J Appl Physiol. 2010;108(5):1055-9. doi: 10.1007/s00421-009-1313-1. [PubMed: 20012445].

45. Kamath MV, Fallen EL, McKelvie R. Effects of steady state exercise on the power spectrum of heart rate variability. Med Sci Sports Exerc. 1991;23(4):428-34. [PubMed: 2056900].

46. Halliwill JR, Taylor JA, Hartwig TD, Eckberg DL. Augmented baroreflex heart rate gain after moderate-intensity, dynamic exercise. Am J Physiol. 1996;270(2 Pt 2):R420-6. doi: 10.1152/ajpregu.1996.270.2.R420. [PubMed: 8779874].

47. Halliwill JR. Mechanisms and clinical implications of post-exercise hypotension in humans. Exerc Sport Sci Rev. 2001;29(2):65-70. [PubMed: 11337825].

48. Iellamo F. Neural mechanisms of cardiovascular regulation during exercise. Auton Neurosci. 2001;90(1-2):66-75. doi: 10.1016/S15660702(01)00269-7. [PubMed: 11485294].

49. Garrett WE, Kirkendall DT. Exercise and sport science. Lippincott Williams \& Wilkins; 2000.

50. McInnes SE, Carlson JS, Jones CJ, McKenna MJ. The physiological load imposed on basketball players during competition. J Sports Sci. 1995;13(5):387-97. doi: 10.1080/02640419508732254. [PubMed: 8558625].

51. Reilly T, Borrie A. Physiology applied to field hockey. Sports Med. 1992;14(1):10-26. [PubMed: 1641540].

52. Da Silva DF, Verri SM, Nakamura FY, Machado FA. Longitudinal changes in cardiac autonomic function and aerobic fitness indices in endurance runners: a case study with a high-level team. Eur J Sport Sci. 2014;14(5):443-51. doi: 10.1080/17461391.2013.832802. [PubMed: 23998661]. 